\title{
A atuação da metafunção textual nas cláusulas relativas apositivas "desgarradas"
}

\author{
The performance of the textual metafunction in the "detached" \\ appositive relative clauses
}

\author{
Karen Pereira Fernandes de Souza ${ }^{1}$
}

\begin{abstract}
Resumo: Baseado na Gramática Sistêmico-Funcional de Halliday e Matthiessen (2014), este artigo propõe a análise da atuação da metafunção textual (eixo Mensagem) - estrutura temática e estrutura informacional - nas cláusulas relativas apositivas "desgarradas". Foram selecionados 500 dados escritos da plataforma Corpus do Português, amostra online de textos lusófonos, coletados entre 2015 e 2016 e usamos a ferramenta GoldVarb X (SANKOFF; TAGLIAMONTE, 2005) para analisar as frequências. Os resultados mostraram que a cláusula observada é adjacente ao referente em $92,8 \%$ dos casos, construída categoricamente por um tema textual e tema tópico, além de ter uma estrutura de Tema-Rema, características herdadas da cláusula não "desgarrada". Também observamos que a cláusula se estrutura $100 \%$ das vezes como não marcada para o estatuto informacional (Dado-Novo) e, em 70,6\% dos casos, observamos uma preferência do usuário pelo grau de informatividade baixo.
\end{abstract}

Palavras-chaves: Cláusula relativa apositiva “desgarrada”. GSF. Estrutura temática. Estrutura informacional.

Abstract: Based on the Functional-Systemic Grammar of Halliday and Matthiessen (2014), this article aims the analysis of the performance of the textual metafunction (Message axis) thematic structure and informational structure - on the "detached" appositive relative clauses. We selected 500 written data from the Corpus of the Portuguese platform, an online corpus of lusophone texts collected between 2015 and 2016 and we used the GoldVarb X tool (SANKOFF; TAGLIAMONTE, 2005) to analyze the frequencies. The results showed that the observed clause is adjacent to the reference in $92.8 \%$ of the cases, constructed categorically by a textual theme and topical theme, besides having a Theme-Rhema structure, characteristics inherited from the non-"detached" clause. We also observed that the clause is structured $100 \%$ as unmarked for the information status (Given-New) and, in $70.6 \%$ of the cases, we observed a preference of the user for the low degree of information.

Keywords: "Detached" appositive relative clause. FSG. Thematic structure. Informational structure.

1 Universidade Federal do Rio de Janeiro, Rio de Janeiro, RJ, Brasil. Endereço eletrônico: karen_pf_souza@hotmail.com. 


\section{Introdução}

Após vários estudos descritivos sobre as cláusulas relativas apositivas "desgarradas" na modalidade escrita (SOUZA, 2016; SOUZA, 2019; SOUZA, 2020; SOUZA; RODRIGUES, 2018; SOUZA; SILVESTRE, 2018), partimos do pressuposto de que essas estruturas são caracterizadas como cláusulas hipotáticas, conforme a Gramática SistêmicoFuncional - GSF (HALLIDAY; MATTHIESSEN, 2014). Se são hipotáticas, significa dizer que a ligação estabelecida entre cláusula relativa apositiva e seu núcleo se dá pela organização do discurso (eixo semântico-pragmático), porque a conexão sintática entre as cláusulas, via hipotaxe, é mais frouxa se comparada ao vínculo existente em cláusulas complexas por encaixamento, visto ser um grau de ligação mais integrado.

Como nos pautamos em uma base fundamentalmente funcionalista, é imprescindível agregar o aspecto semântico à descrição dessa estrutura e, por isso, o conceito de Unidade Informacional - UI (CHAFE, 1980) é posto em cena. Respaldado nas observações feitas sobre a consciência humana (foco, memória curta etc.), ele afirma que a fala espontânea do ser humano é realizada por "jatos de linguagem", havendo muitas pausas, hesitações e falsos começos durante a comunicação, ou seja, a produção oral é composta por meio de um conjunto de "unidades informacionais". A composição desses "blocos de informação" autônomos forma um todo coeso e de sentido global e cada UI é marcada por um contorno entonacional próprio de curvatura descendente (final de frase).

Quanto à forma como as cláusulas relativas apositivas "desgarradas" se apresentam, na modalidade escrita, elas se materializam sempre após um ponto final por ser o sinal gráfico que limita uma unidade comunicativa à esquerda e à direita. Dahlet (2006, p. 130) mostra que os sinais sequenciais (como o ponto final) estão relacionados à segmentação das sequências textuais, mas, a depender do objetivo comunicativo do usuário da língua, os sinais sequenciais podem adquirir uma função enunciativo-pragmática. Essa função já havia sido estudada por Decat (2011) ao observar o fenômeno do "desgarramento" propriamente dito (em cláusulas relativas e circunstanciais), pois o uso desse fenômeno desempenha a função de apontar para um propósito comunicativo; em outras palavras, a utilização da cláusula "desgarrada", formalmente separada de seu núcleo por meio de um ponto final, serve para sinalizar ao leitor/interlocutor a importância da ideia que ali se veicula, isto é, a parte relevante a ser enunciada. Assim, seu uso é uma opção organizacional do texto ao refletir uma decisão do usuário da língua, enfatizando, focalizando, realçando uma ideia, buscando assim uma maior força argumentativa em seu discurso. 
Nesse sentido, o objetivo desse trabalho é mostrar a maneira como os significados são organizados dentro da cláusula para formar um todo coeso em forma de Texto, através da metafunção textual da GSF. Centramos o estudo no interior da cláusula sem esquecer o seu entorno, uma vez que a cláusula relativa apositiva "desgarrada" está apoiada semanticamente em um sintagma nominal ou porção textual previamente dado no discurso. Assim, o objetivo específico é ver como a Estrutura Temática e Estrutura da Informação do sistema TEMÁTICO atuam na formação dos significados. Nossa hipótese é a de que o escrevente usa intencionalmente a ruptura sintática da relativa apositiva e seu núcleo com o intuito de dirigir o leitor para o Rema e, ao mesmo tempo, preparar o leitor para uma informação com o status de Nova. Estudar a metafunção textual é bastante relevante uma vez que há poucos trabalhos sobre a cláusula relativa apositiva "desgarrada" que utilizam a GSF.

Selecionamos 500 cláusulas do Corpus do Português (DAVIES, 2016) que reúne variados gêneros em língua portuguesa coletados na Internet e, por isso, ele conta com mais de um bilhão de palavras retiradas de diferentes sites lusófonos (Brasil, Portugal, Angola e Moçambique). Como metodologia, fizemos uma análise qualitativa e quantitativa dos padrões da estrutura da informação e da estrutura temática dado a dado e utilizamos a ferramenta computacional GoldVarb X (SANKOFF; TAGLIAMONTE, 2005) para nos ajudar com a quantificação e as tabelas de frequências.

Assim, além dessa Introdução, a próxima seção aborda a fundamentação teórica calcada na Gramática Sistêmico-Funcional (GSF) com ênfase no sistema TEMÁTICO; em seguida, temos a seção Corpus e métodos para mostrar os procedimentos adotados. Após, apresentamos os resultados da Análise e padrões da estrutura temática e, após, seguem as discussões sobre a Análise e padrões da estrutura informacional. Fechamos com as Considerações finais e Referências.

\section{Gramática Sistêmico-Funcional (GSF)}

Na Linguística Sistêmico-Funcional (LSF), a linguagem não é vista como uma lista de estruturas possíveis no sistema da língua, como um conjunto de regras fixo, aqui, ela é vista como um conjunto de possibilidades, um sistema socio-semiótico de modo que o homem estrutura a sua fala de acordo com o que ele experiencia em seu meio ambiente. A língua serve para interagir, trocar e construir significados em seu meio social. Portanto, estamos diante de uma teoria de base semântica e de uma língua que é vista como um potencial de significados. Tendo esse conceito estabelecido, Michael Halliday sistematiza em 1985 a Gramática Sistêmico-Funcional (GSF), na qual a unidade básica de significado é a cláusula. 
Se a linguagem é usada para dar sentido às experiências humanas e para realizar interações com outras pessoas no meio social, então, é necessário que a gramática de uma língua interaja com o que acontece fora da linguagem. Sendo assim, o homem interpreta o seu meio externo e/ou o seu interior e, concomitantemente, precisa organizar esses significados em forma de um texto articulado. Esse texto é um constructo de significados elaborado por meio de trocas entre indivíduos em uma situação de comunicação (contexto), organizado através da seleção e composição de camadas linguísticas (plano do conteúdo) e materializado sonoramente ou graficamente (plano da expressão).

Se as funções básicas da linguagem são (i) fazer sentido às nossas experiências e (ii) fazer nos relacionar uns com os outros, então, a linguagem tem propósitos/objetivos que a GSF chama de metafunções da linguagem. Segundo Halliday e Matthiessen (2014), os três componentes do sistema de significados (estrato semântico) são: (a) metafunção ideacional, que expressa nossas experiências, tanto no mundo material (ações e eventos no mundo exterior), quanto no mundo psicológico (percepção, imaginação, emoção no mundo interior); (b) metafunção interpessoal, que expõe os papéis desempenhados pelos participantes de uma interação social; (c) metafunção textual, que organiza os significados das experiências e das relações entre os participantes em um todo coerente. Na perspectiva hallidayana, a cláusula é a menor unidade significativa da GSF, porque ela engloba:

[...] três significados: uma representação (significado como conteúdo); uma troca (significado como forma de ação); e uma mensagem (significado como relevância para o contexto). Todas as línguas nos moldes da LSF, são organizadas em torno de dois significados principais: o ideacional e o interpessoal. Esses significados, a que se associa um terceiro, o textual, são as manifestações no sistema linguístico dos dois propósitos mais gerais que fundamentam os usos da linguagem: entender o ambiente e influir sobre os outros. (CUNHA; SOUZA, 2011, p. 28, grifos no original)

Como já postulado na teoria geral do Funcionalismo, na GSF, elementos linguísticos isolados nada significam; portanto, para significar, as três metafunções da linguagem precisam estar presentes.

Halliday e Matthiessen (2014) idealizam a GSF como uma tríade indissociável de sistema de valores, mas não significa que não possamos dar ênfase a apenas um dos três eixos. Como queremos mostrar a atuação da metafunção textual nas cláusulas relativas apositivas "desgarradas", a partir daqui, deixaremos em evidência o sistema TEMÁTICO da metafunção Textual (eixo da Mensagem), destacado em preto na Figura 1 a seguir: 
Figura 1 - Escala de níveis da GSF

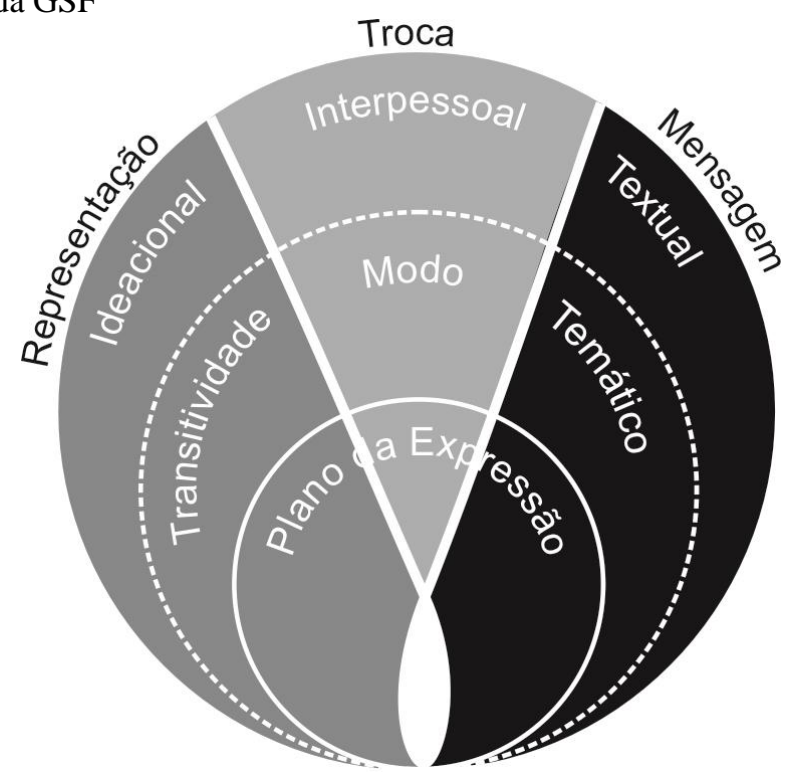

Fonte: Adaptado de Souza (2020, p. 71).

Caminhando pelo prisma da cláusula como mensagem, a metafunção textual é codificada pelo sistema TEMÁTICO. Esse sistema é responsável por organizar os significados do mundo externo e psicológico do comunicante (eixo da Representação) e os significados interpessoais entre os participantes da comunicação (eixo da Troca) em um todo coeso e coerente. No âmbito da léxico-gramática, há dois sistemas atuando em conjunto no fluxo de informação: Estrutura Temática e Estrutura Informacional.

Na Estrutura Temática, vemos como o escrevente orienta, ou seja, direciona o leitor na compreensão da sua mensagem e como ocorre o fluxo de informação. Observamos, então, que a cláusula é composta por dois componentes: o Tema, em que o falante escolhe o ponto de partida, ou seja, o destaque (por isso, é posto em primeiro lugar na composição da cláusula como "sujeito psicológico"), e o Rema, a parte em que o falante desenvolve as ideias que estão presentes no Tema, ou seja, a informação importante para o ouvinte/leitor. Segundo Halliday e Matthiessen (2014, p. 112), o Tema de uma cláusula se estende desde o começo da sentença até, e incluindo, o primeiro elemento com função experiencial; todo o resto constitui o Rema.

Como a função experiencial está envolvida na identificação do Tema, podemos ter em língua portuguesa, tema múltiplo, de modo que a cláusula pode conter mais de um tema em sua composição. Portanto, se o elemento realiza uma função do sistema de TRANSITIVIDADE (participante, processo ou circunstância), ele é chamado de Tema tópico; se for do sistema de MODO (vocativo, adjunto modal, elemento QU-, metáforas interpessoais), ele é chamado de 
Tema interpessoal, e, se for do sistema TEMÁTICO (conjunções, sequencializadores, elementos continuativos), ele é chamado de Tema textual.

Como trabalhamos com cláusula complexa, precisamos ter uma visão macro da estrutura. Nesse sentido, a cláusula núcleo passa a ocupar a posição de Tema e a cláusula satélite passa a exercer a função de Rema - sem nos esquecermos de analisar a estrutura micro de cada cláusula individualmente. Observemos o exemplo a seguir:

Quadro 1 - Tema-Rema do complexo oracional

\begin{tabular}{|l|c|c|c|c|}
\hline $\begin{array}{l}\text { A partir de } \\
\text { agora, }\end{array}$ & $\begin{array}{l}\text { o pagamento das horas } \\
\text { extras deve ter início a } \\
\text { partir das 18h30, }\end{array}$ & embora & tradicionalmente & $\begin{array}{l}\text { os trabalhos } \\
\text { legislativos se } \\
\text { estendam pela } \\
\text { noite. }\end{array}$ \\
\hline Tema tópico & Rema & $\begin{array}{c}\text { Tema } \\
\text { textual }\end{array}$ & Tema Tópico & Rema \\
\hline \multicolumn{2}{|c|}{ TEMA } & \multicolumn{2}{|c|}{ REMA } \\
\hline
\end{tabular}

Fonte: Fuzer; Cabral (2014, p. 140).

$\mathrm{Na}$ cláusula satélite, o primeiro elemento experiencial é a circunstância "tradicionalmente"; então, "embora tradicionalmente" será o Tema e a partir dele tem-se o Rema e toda a cláusula satélite é o Rema da cláusula núcleo "a partir de agora, o pagamento das horas extras deve ter início a partir das 18h30".

Já nas cláusulas relativas, Halliday e Matthiessen (2014) garantem que os conectivos carregam duas funções temáticas simultaneamente: Tema textual e Tema tópico. Tal fato ocorre porque o elemento relativo carrega em si a função de se conectar a outras cláusulas ou sintagmas, como as demais conjunções, sequencializadores ou elementos continuativos, bem como exercer função experiencial no interior da cláusula relativa. No exemplo em que se segue, o conectivo "em que" recebe a classificação de Tema tópico e Tema textual ao mesmo tempo. Vejamos:

Quadro 2 - Tema de uma cláusula relativa

\begin{tabular}{|c|c|c|c|}
\hline (the book is faithful to the time) & \multicolumn{2}{|c|}{ in which } & it took place. \\
\hline (o livro é fiel à época) & \multicolumn{2}{|c|}{ em que } & ele foi escrito. \\
\hline & Tema textual & Tema tópico & Rema \\
\hline & \multicolumn{2}{|c|}{ TEMA } & REMA \\
\hline
\end{tabular}

Fonte: Adaptado de Halliday; Matthiessen (2014, p. 112)

Na perspectiva hallidayana, a Estrutura da Informação, como o próprio nome diz, estuda uma porção de informação. Na Gramática Sistêmico-Funcional, informação é a tensão entre o que já é conhecido, partilhado entre os participantes do ato comunicativo - Dado-e 
aquilo que é desconhecido pelo leitor, imprevisível - Novo. É a interação entre o Novo e o Dado que gera informação no sentido linguístico. Cada unidade de informação (visto também como uma unidade informacional) consiste em dois aspectos: (i) Novo, marcado por proeminência/saliência, e (ii) Dado, que antecede o elemento Novo em posição não marcada em português. Portanto, o que é tratado como "recuperável" (Dado) é a informação que já foi mencionada no cotexto; mas essa não é a única possibilidade, pois pode ser algo que esteja na situação externa ao texto (elementos gramaticais exofóricos - dêiticos).

Os linguistas deixam claro, em sua teoria, que existe uma estreita relação semântica entre a Estrutura Temática e a Estrutura da Informação, quando os elementos estão postos de forma não marcada. Mas, apesar de serem relacionados, Dado-Novo e Tema-Rema nem sempre coincidem. Isso acontece porque o Tema é o que o escritor escolhe para tomar como seu ponto de partida; já o Dado é o que é conhecido pelo leitor. Então, Tema-Rema está na perspectiva do escritor e Dado-Novo está orientado na perspectiva do leitor, mas ambos são selecionados pelo escritor durante a produção do texto, pois é escritor que organiza o fluxo de informação.

Apoiados nos conceitos ora apresentados nessa seção de revisão de literatura (com foco na metafunção textual da cláusula), a próxima seção traz a caracterização do corpus utilizado e explica como a análise dos dados foi procedida e os objetivos específicos.

\section{Corpus e métodos}

O Corpus do Português (DAVIES, 2016) colheu quase um milhão de páginas eletrônicas de diferentes sites lusófonos. Optamos por utilizar os textos contidos no compilado Web/Dialetos, pois lá estão reunidos textos do período compreendido entre 2015 e 2016 de variados gêneros publicados na Internet. Esse corpus foi escolhido por ser digital, a sua plataforma facilitava a busca pelos dados.

Dentro da plataforma, após digitar na caixa de pesquisa os formatos introdutórios desejados, selecionamos 100 dados aleatórios para cada conector das cláusulas relativas apositivas "desgarradas", totalizando 500 cláusulas para análise nessa pesquisa, conforme a distribuição na Tabela 1. Muitas estruturas precisaram ser eliminadas durante o processo de filtragem, já que o formato das cláusulas em estudo pode ser facilmente confundido com o início de outras estruturas da língua portuguesa. O programa GoldVarb X (SANKOFF; TAGLIAMONTE, 2005) foi utilizado para auxiliar na quantificação das frequências e elaboração das tabelas. 
Tabela 1 - Distribuição quantitativa dos dados por formato

\begin{tabular}{ccc}
\hline ORDEM & FORMATO & QUANT. \\
\hline 1. & {$[$. Que $]$} & 100 \\
2. & {$[. \text { O que }]^{2}$} & 100 \\
3. & {$[. \text { O qual] }]^{3}$} & 100 \\
4. & {$[$. Cujo] } & 100 \\
5. & {$[$. Onde] } & 100 \\
\hline & TOTAL: & $\mathbf{5 0 0}$ \\
\hline
\end{tabular}

Fonte: Souza (2020).

Com relação aos procedimentos de análise da Estrutura Temática, Koch e Elias (2008, p. 131) apontam para a Retomada como uma operação responsável pela conservação de objetos discursivos previamente fornecidos no contexto na posição focal dando origem aos diferentes tipos de cadeias referenciais e/ou coesivas. Halliday e Matthiessen (2014) afirmam que essa é uma das táticas previstas pelo Sistema da língua que permite ao usuário ultrapassar os limites da combinação de cláusulas para formar textos maiores e mais complexos. Portanto, torna-se imprescindível a contagem dos elementos intervenientes entre o núcleo e a cláusula "desgarrada" - e quantificá-los - chamamos esse aspecto de Posição da cláusula; a exploração de quais componentes temáticos (tema textual, interpessoal, tópico) se fazem presentes na estrutura temática das cláusulas relativas apositivas "desgarradas" e a busca por um padrão de estruturação temática da cláusula visando à progressão textual - analisamos essa última característica dentro do aspecto Estrutura Temática.

Com relação aos procedimentos de análise do Estatuto Informacional, Halliday e Matthiessen (2014, p.118) mostram que o elemento Novo de estruturas não marcadas aparece no final da unidade de informação. Aqui, o que nos é caro é ver o status informacional dentro da cláusula, pois queremos observar de que maneira funciona a estrutura da informação (Dado-Novo) de uma cláusula relativa apositiva "desgarrada" e o seu entorno imediato chamamos essa subseção de Estatuto Informacional. Em seguida, procedemos com a contabilização das UI dentro do período de combinação de cláusulas - chamamos esse aspecto de Grau de Informatividade. Esses esquemas auxiliarão na compreensão de como o escrevente organiza, distribui e cede informações pouco a pouco na construção do seu texto, movimentando-se para trás e para frente, tornando o todo fluido e coeso. Passemos às discussões dos resultados.

\footnotetext{
${ }^{2}$ Conector invariável.

${ }^{3}$ Coletamos dados com variação de gênero, mas não de plural por questões metodológicas.

${ }^{4}$ Coletamos dados com variação de gênero, mas não de plural por questões metodológicas.
} 


\section{Análise e padrões da estrutura temática}

Iniciamos a discussão dos resultados pela Posição da cláusula relativa. Segundo a literatura, as cláusulas relativas estão sempre adjacentes ao nome ou à porção textual referente e por isso, julgamos importante observar o posicionamento entre a cláusula e seu referente. $\mathrm{O}$ resultado, em 500 ocorrências, nos mostra que estamos diante de um caso categórico, pois 92,8\% (464 oco.) dos dados foram classificados como adjacentes ao referente, contra 7,2\% (36 oco.) como distantes do referente, confirmando, assim, a descrição da gramática tradicional. Entretanto, ainda que o índice seja bastante elevado para a característica adjacente, vale a pena mostrar como as relativas apositivas "desgarradas" também podem surgir distantes de seu referente, e devemos considerar esses poucos casos para fins de análise por serem possíveis na língua portuguesa. Vejamos alguns exemplos:

Exemplo (1): a. E, por outro lado, há na obra de Freyre também uma profunda melancolia, porque toda ela estrutura-se em torno de um mundo que já havia desaparecido. Ou, bem, estava prestes a desaparecer. Um mundo na iminência de virar espectro. Mundo ruinoso. Condenado. Cheio de rachaduras fatais. Que já tinha conhecido seu momento mais cintilante. Ou podia divisá-lo ao longe. Algo que nos remete, ainda uma vez, para o Benjamin que nos ensina que "aquilo que se sabe estar prestes a não se ter mais diante de si torna-se imagem”.

b. Uma alternativa socialista é baseada no interesse social e não na propriedade privada e produção, no controle democrático de produtores e consumidores e não da elite burguesa. Onde o lucro não determina o que deve ser produzido, e onde desigualdade e relações hierárquicas de poder e riqueza são trocados por cooperação, igualdade e respeito mútuo, a nível nacional e internacional. Uma economia democraticamente planeada forneceria recursos para garantir uma renda justa e uma independência económica para todos.

c. Este é o tipo de homem que *nunca* trai uma mulher. Que é sempre autêntico e honesto. Que se sente fascinado por ela e a celebra. Que é interessante. Que tem paixões na vida e sabe qual é a sua missão. Que é divertido. Cuja consciência está (muito) acima da média. Não tem nada a ver com "«temos instintos animalescos, gostamos de discutir, gostamos que o sangue ferva"». Isso é ridículo.

No Exemplo 1, a cláusula relativa apositiva "desgarrada" - Que já tinha conhecido seu momento mais cintilante - da letra (a) tece um comentário avaliativo positivo sobre o referente "mundo que já havia desaparecido". O escrevente apresenta outros atributos em forma de cláusulas e grupos nominais que vão distanciando cada vez mais o referente da cláusula destacada. Um outro exemplo de distanciamento pode ser visto na letra (b), em que o referente "uma alternativa socialista" da cláusula "desgarrada" Onde o lucro não determina o que deve ser produzido está presente na cláusula primária do período anterior. O que os distancia é a cláusula paratática que expande por extensão a cláusula inicial com vários elementos coordenados. Na letra (c), há um outro exemplo de cláusula relativa apositiva 
"desgarrada" - Cuja consciência está (muito) acima da média - distante de seu referente "homem que nunca trai uma mulher”, após uma série de cláusulas relativas autônomas.

Avançando a análise para a composição da Estrutura temática das cláusulas, o componente Tema das relativas apositivas "desgarradas" é constituído por um tema textual e um tema tópico em $100 \%$ dos casos. Não verificamos, em nenhuma cláusula, o tema interpessoal como elemento interveniente na construção temática. Como a estrutura da cláusula relativa apositiva (não "desgarrada") é relativamente estável em nossa língua, observamos a manutenção/ conservação dessas funções nas cláusulas relativas apositivas "desgarradas".

Segundo Halliday e Matthiessen (2014, p. 112), o Tema é o ponto de partida da cláusula, pois é ele que direciona o leitor para a mensagem considerada importante (pelo escrevente) para o conteúdo presente no Rema. A estrutura temática da cláusula relativa apositiva "desgarrada" é constituída, como já discutido, categoricamente por um único conectivo que exerce a função de tema textual no sistema TEMÁTICO responsável pela retomada anafórica do referente e, simultaneamente, exerce a função de tema tópico (função experiencial) no sistema de TRANSITIVIDADE, como pode ser visto nos exemplos a seguir:

\begin{tabular}{|c|c|c|c|c|}
\hline \multirow{2}{*}{$\begin{array}{l}\text { Inimigo de qualquer autoridade moral, apelidou } \\
\text { seu professor de "«Mestre Linguiça"», outra } \\
\text { referência a malfadada iguaria suína. Seu } \\
\text { Madruga, que têm muito trabalho para continuar } \\
\text { sem trabalhar, cometia o pecado da preguiça. } \\
\text { Exigem redobrados esforços suas estratégias de } \\
\text { fuga, para não pagar [os indefectíveis } 14 \text { meses } \\
\text { de aluguel]. }\end{array}$} & \multicolumn{2}{|c|}{ Que } & \multirow{2}{*}{$\begin{array}{c}\text { nunca se } \\
\text { tornam } 15 \\
\text { meses, } \\
\text { Rema }\end{array}$} & \multirow[t]{2}{*}{$\begin{array}{l}\text { denotando que a } \\
\text { passagem do } \\
\text { tempo está } \\
\text { suspensa. }\end{array}$} \\
\hline & $\begin{array}{l}\text { Tema } \\
\text { textual }\end{array}$ & $\begin{array}{l}\text { Tema } \\
\text { tópico }\end{array}$ & & \\
\hline
\end{tabular}

Fonte: Corpus do Português (DAVIES, 2018). 


\begin{tabular}{|c|c|c|c|c|}
\hline \multirow{2}{*}{$\begin{array}{l}\text { Na Aldeia - por uma questão de sensibilidade e } \\
\text { de gosto - não existem fotografias de abortos. } \\
\text { No entanto, considerando que essas fotos podem } \\
\text { ser importantes para ajudar certas pessoas a } \\
\text { entenderem melhor que coisa é o aborto, } \\
\text { deixamos aqui duas ligações para lugares onde } \\
\text { encontra essas esclarecedoras imagens. [São } \\
\text { imagens duras, chocantes]. }\end{array}$} & \multicolumn{2}{|c|}{ O que } & \multirow{2}{*}{$\begin{array}{c}\text { pode ser } \\
\text { mau...ou } \\
\text { bom. } \\
\text { Rema }\end{array}$} & \multirow{2}{*}{ Depende de si. } \\
\hline & $\begin{array}{c}\text { Tema } \\
\text { textual }\end{array}$ & $\begin{array}{l}\text { Tema } \\
\text { tópico }\end{array}$ & & \\
\hline
\end{tabular}

Fonte: Corpus do Português (DAVIES, 2018).

\begin{tabular}{|c|c|c|c|c|}
\hline \multirow{2}{*}{$\begin{array}{l}\text { Em } 2005 \text { a ECT possuia um efetivo total de } \\
105334 \text { empregados, compostos da seguinte } \\
\text { forma: } 81.231 \text {-- Homens e } 24103 \text { mulheres e } \\
7011 \text { empregados negros. Como explicar isso no } \\
\text { Brasil onde a maioria é negra? Seria necessário } \\
\text { debater como eram os processos de contratação } \\
\text { [antes do advento do concurso público } \\
\text { obrigatório]. }\end{array}$} & \multicolumn{2}{|c|}{ Onde } & \multirow{2}{*}{$\begin{array}{c}\text { a contratação } \\
\text { se dava por } \\
\text { indicação do } \\
\text { amigo, do } \\
\text { amigo. } \\
\text { Rema }\end{array}$} & $\begin{array}{l}\text { Quando se reporta } \\
\text { a ocupação de } \\
\text { funções o cenário } \\
\text { em } 2005 \text { estava } \\
\text { assim composto: } \\
\text { [...] }\end{array}$ \\
\hline & $\begin{array}{c}\text { Tema } \\
\text { textual }\end{array}$ & $\begin{array}{l}\text { Tema } \\
\text { tópico }\end{array}$ & & \\
\hline
\end{tabular}

Fonte: Corpus do Português (DAVIES, 2018).

Analisando o tipo de comentário das cláusulas destacadas em negrito, no Exemplo 2 (Quadro 3), podemos notar um comentário sobre a suspensão do tempo que não alcança os 15 meses de aluguel atrasado - Que nunca se tornam 15 meses; no Exemplo 3 (Quadro 4), o escrevente expressa a sua dúvida sobre ser boa ou ruim a exposição das imagens de aborto com a cláusula "desgarrada" - O que pode ser mau... ou bom; no Exemplo 4 (Quadro 5), o escrevente comenta negativamente a forma de contratação dos funcionários dos Correios antes de ser por meio de um concurso público - Onde a contratação se dava por indicação do amigo, do amigo.

Comparando as estruturas temáticas dos três exemplos anteriores, os conectores "Que", "O que" e "Onde" exercem as funções de ligar semanticamente as duas cláusulas por referenciação (tema textual) e de exercer a mesma função sintática do elemento substituído (tema tópico) no interior da cláusula hipotática. Para Halliday e Matthiessen (2014, p. 117), não existe cláusula descontextualizada e, caso ela não tenha apoio em um material linguístico, seu apoio estará no ambiente situacional. Nos exemplos fornecidos, todas as cláusulas do corpus estão situadas no cotexto imediatamente anterior, ou seja, são recuperáveis no meio linguístico: no Exemplo 2 (Quadro 3), os indefectíveis 14 meses de aluguel; no Exemplo 3 (Quadro 4), são imagens duras, chocantes; no Exemplo 4 (Quadro 5), antes do advento do 
concurso público obrigatório, seja um grupo nominal, um grupo adverbial ou uma porção textual.

Após a análise de todos os dados observados, podemos afirmar, com segurança que a cláusula relativa apositiva "desgarrada" contribui, de forma expressiva, para a sequenciação textual. Do ponto de vista organizacional das informações, a relação Tema-Rema auxilia no processamento do texto, já que os escritores "não podem utilizar a entonação para marcar quais informações são mais importantes e quais ficam em segundo plano" (FUZER; CABRAL, 2014, p. 141). Assim, a Progressão temática acontece, pois o Rema presente no período anterior à cláusula relativa apositiva "desgarrada" passa a ser o Tema da cláusula seguinte (cf. Quadro 6), de acordo com os 92,8\% (464 oco.) dos casos adjacentes ao referente. Preferimos, aqui, não classificar o tipo de progressão temática das relativas apositivas "desgarradas", porque não estamos analisando o entorno da cláusula macrotextualmente, o que se faz necessário para atestar o tipo de progressão sequencial. Apenas salientemos a contribuição das relativas apositivas "desgarradas" na organização e no desenvolvimento das informações no Texto. Vejamos no Quadro 6, a seguir, o padrão:

Quadro 6 - Esquema de progressão temática da cláusula relativa apositiva "desgarrada"

Inimigo de qualquer autoridade moral, apelidou seu professor de "«Mestre Linguiça"», outra referência a malfadada iguaria suína. Seu Madruga, que têm muito trabalho para continuar sem trabalhar, cometia o pecado de a preguiça. Exigem redobrados esforços suas estratégias de fuga, para não pagar [os indefectíveis 14 meses de aluguel.

$\mathrm{Na}$ Aldeia - por uma questão de sensibilidade e de gosto - não existem fotografias de abortos. No entanto, considerando que essas fotos podem ser importantes para ajudar certas pessoas a entenderem melhor que coisa é o aborto, deixamos aqui duas ligações para lugares onde encontra essas esclarecedoras imagens. [São imagens duras, chocantes].

Em 2005 a ECT possuia um efetivo total de 105334 empregados, compostos da seguinte forma: 81.231 -- Homens e 24103 mulheres e 7011 empregados negros. Como explicar isso no Brasil onde a maioria é negra? Seria necessário debater como eram os processos de contratação [antes do advento do concurso público

Que nunca se tornam 15 meses, denotando que a passagem do tempo está suspensa. obrigatório].

Pessoas conhecidas, principalmente nas rodinhas de conversa que se formam nas suas costas, como o famoso "«pavio curto"». Para ilustrar a questão, podemos dizer que as criaturas de pavio curto são aquelas que, ao notarem que não estão agradando, sacam imediatamente [as duas pedras que trazem na manga para qualquer eventualidade].

O que pode ser mau... ou bom.

Onde a contratação se dava por indicação do amigo, do amigo.

\begin{tabular}{rllll} 
Rema (a) $\longrightarrow$ & Tema (b) & Rema (b) \\
\hline
\end{tabular}

Fonte: Souza (2020). 
Como pode ser visto no Quadro (6), observamos a relação existente entre o referente presente na primeira coluna e a cláusula "desgarrada" negritada na segunda coluna. Verificamos o padrão temático da seguinte forma: o Rema (ou parte do Rema) da cláusula dominante (a) passa a ser o Tema da cláusula "dependente" (b). Logo, o movimento é sempre progressivo, pois o assunto retomado é encapsulado pelo conectivo (tema textual), e o foco informacional se direciona para o Rema da cláusula relativa apositiva "desgarrada".

Conforme a caracterização das cláusulas relativas na Introdução, elas não são conectadas sintaticamente ao seu referente, atestadas nos exemplos fornecidos anteriormente. Elas se realizam de forma autônoma e, por essa razão, se manifestam após um sinal gráfico de ponto final. $\mathrm{O}$ escrevente faz uso dessa pontuação para agregar ainda mais valor significativo ao conteúdo presente no Rema da cláusula "desgarrada". Assim, percebe-se haver uma intenção premeditada no uso do "desgarramento" por parte do escrevente, pois ele direciona a atenção do leitor para o conteúdo do comentário presente no Rema, destacando-o/enfatizandoo. Como é o significado que importa ser transmitido, vejamos, na próxima seção, o padrão da Estrutura da Informação, na perspectiva da GSF.

\section{Análise e padrões da estrutura informacional}

Como vimos, a Estrutura da Informação é a quantidade de informação e nem sempre corresponde ao tamanho de uma cláusula. Se a Informação é o vínculo entre o que já é conhecido e aquilo que é desconhecido pelo leitor, então, cada unidade de informação consiste em dois aspectos: Dado e Novo. Em 100\% dos casos, a cláusula relativa apositiva “desgarrada" se configura segundo uma posição não marcada: Dado-Novo. Como a cláusula relativa apositiva canônica é uma estrutura relativamente estável no sistema da língua, visto que a composição da informação é Dado-Novo, observamos a manutenção dessa característica nas cláusulas “desgarradas". Assim, temos a retomada de um elemento já fornecido no discurso (função desempenhada pelo conector), seguida da informação que verdadeiramente importa: o comentário. É o conteúdo do comentário que é o elemento Novo e que recebe, assim, o foco informacional. Deve-se ressaltar que também não identificamos nenhum dado que tivesse a antecipação do elemento Novo sobre o elemento Dado.

Para essa investigação, trabalhamos apenas com a modalidade escrita da língua. Sendo assim, utilizamos os recursos linguísticos disponíveis no texto para as análises. Como a estrutura investigada trabalha também como um processo de referenciação, vale ressaltar que Halliday e Matthiessen (2014) postulam que elementos gramaticais endofóricos (retomadas anafóricas de elementos no cotexto) e exofórico (dêiticos do contexto situacional) não 
carregam o foco da informação por serem elementos recuperáveis no cotexto, sendo assim, isso nos leva a afirmar que o conteúdo informacional com status de Novo encontra-se logo após o conectivo (elemento referencial) que recebe o status de Dado. Vejamos alguns exemplos a seguir:

Quadro 7 - Exemplo (5)

\begin{tabular}{|c|c|c|}
$\begin{array}{c}\text { O mínimo que uma pessoa sensata pensa é. } \\
\begin{array}{c}\text { Em fazer exatamente o oposto. Porque esse } \\
\text { pessoalzinho, vocês sabem. [Vivem numa } \\
\text { lógica de Hay gobierno, soy contra]. }\end{array}\end{array}$ & O que não é totalmente ruim. & Longe de isso. \\
\hline Cotexto & Dado & \\
\hline
\end{tabular}

Fonte: Corpus do Português (DAVIES, 2018).

No Exemplo 5 (Quadro 7), por referenciação, o conector [O que] funciona como o elemento Dado da unidade informacional da cláusula relativa apositiva "desgarrada", pois ele retoma a porção textual destacada em negrito mencionada no cotexto - Viver numa lógica de Hay gobierno, soy contra. O elemento Novo coincide justamente com o Rema da proposição - não é totalmente ruim. A avaliação negativa do escrevente sobre o assunto é a novidade, pois ela colabora para a progressão textual, agregando mais informação ao texto. Sendo assim, todo o comentário é classificado como Novo. Textualmente, não é possível indicar qual é o vocábulo mais proeminente, porque tudo dentro do conjunto é importante, ou seja, é uma opinião do escrevente externada pela primeira vez para o leitor.

Quadro 8 - Exemplo (6)

\begin{tabular}{|c|c|c|}
\hline $\begin{array}{l}\text { Há anos um pequeno grupo apaixonado pelo } \\
\text { Peabiru (ao qual eu e meu pai, Rosnel Bond, } \\
\text { pertencemos) a tem apresentado a municípios } \\
\text { de SC, PR, SP. Importante: nenhum de nós } \\
\text { pede pagamento por isto. Somos apenas } \\
\text { motivadores. É [uma idéia aberta, livre, } \\
\text { leve e solta]. }\end{array}$ & $\begin{array}{l}\text { A qual hoje, com variações locais, } \\
\text { funciona em Pitanga (PR), Campo } \\
\text { Mourão (PR) e cidades do interior } \\
\text { e do litoral paulista. }\end{array}$ & $\begin{array}{c}\text { Em SC, um } \\
\text { Parque Natural } \\
\text { Municipal } \\
\text { Caminho do } \\
\text { Peabiru foi } \\
\text { implantado em } \\
\text { Barra Velha [...] }\end{array}$ \\
\hline Cotexto & Dado & \\
\hline
\end{tabular}

Fonte: Corpus do Português (DAVIES, 2018).

No Exemplo 6 (Quadro 8), o elemento Dado da cláusula relativa apositiva "desgarrada" repousa sobre o conector [A qual] que recupera o grupo nominal negritado no cotexto - uma ideia aberta, livre, leve e solta. O elemento Novo está situado no Rema da proposição - hoje, com variações locais, funciona em Pitanga (PR), Campo Mourão (PR) $e$ cidades do interior e do litoral paulista. O comentário descritivo realizado pelo escrevente sobre o Tema é a novidade da unidade informacional e tudo ali é importante: (i) "hoje" se opõe a "há anos" presente no cotexto; (ii) "com variações locais" porque a ideia aberta não 
funciona igual em todas as cidades; (iii) já é possível encontrar a ideia aberta nas cidades Pitanga, Campo Mourão e cidades no interior e litoral paulista. Logo, se uma dessas especificações não aparecer, fará falta. Fará falta, porque o leitor não tem conhecimento sobre essas informações. O comentário inteiro permite que o texto se desenvolva mais e, por isso, ele foi classificado como Novo.

Quadro 9 - Exemplo (7)

\begin{tabular}{|c|c|c|}
\hline $\begin{array}{c}\text { DAS COISAS QUE A GENTE NEM SABIA } \\
\text { QUE PODIA FAZER... Até aí, nada demais - } \\
\text { - minha mãe me criou super consciente em } \\
\text { relação a esse tipo de coisa, então eu sou } \\
\text { daquelas que vai religiosamente a cada 6 } \\
\text { meses, faz preventivo e tals. Até porque tenho } \\
\text { histórico de câncer na família. Enfim. Só que } \\
\text { a médica, que é ótima, me pediu [uma } \\
\text { bateria de exames]. }\end{array}$ & $\begin{array}{c}\text { Que também faço a cada 6 meses } \\
\text { (esses eu enrolo mais, rs). }\end{array}$ & $\begin{array}{c}\text { Te juro que não é } \\
\text { bem medo. }\end{array}$ \\
\hline Cotexto & Dado & \\
\hline
\end{tabular}

Fonte: Corpus do Português (DAVIES, 2018).

Seguindo o modelo de Halliday e Matthiessen (2014), a estrutura no exemplo (7) tem o conector [Que] que funciona como o elemento Dado do bloco de informação, pois ele retoma o grupo nominal negritado no cotexto - uma bateria de exames. O elemento Novo, uma vez mais, coincide com o conteúdo da proposição - também faço a cada 6 meses. O comentário realizado pelo escrevente sobre o Tema é a novidade da unidade informacional, o que permite que o texto progrida.

Após analisarmos alguns exemplos de Estrutura da Informação, em cláusulas relativas apositivas "desgarradas", segundo a GSF, vale reforçar o porquê de não adotarmos a perspectiva de Prince (1981) para o tratamento dos nossos dados. A noção de informação Nova que estamos considerando aqui é interna à cláusula, ou seja, temos como base o conteúdo proposicional disposto na própria cláusula e não uma representação mental de novos elementos/novos referentes no discurso. Nossa preocupação é observar como a informação é trabalhada dentro da cláusula ao observar o nível da léxico-gramática, visto que, na Teoria adotada, para uma estrutura ter status de cláusula, ela precisa ter as metafunções ideacional, interpessoal e textual atendidas. Se os estudos de Prince (1981) estivessem sido considerados, precisaríamos expandir a análise para porções maiores no entorno da cláusula, o que não é a nossa intenção aqui. Além disso, precisaríamos adotar a perspectiva da representação dos referentes no discurso, o que não corresponde com a teoria adotada aqui. 
Halliday e Matthiessen (2014, p. 115) afirmam que em casos não marcados, cláusula e unidade informacional são coextensivas, sendo assim, todas as relativas apositivas "desgarradas" do corpus verificado se configuram por meio de uma estrutura não marcada [Dado-Novo], então, pela lógica, consideramos que a própria relativa apositiva "desgarrada" é uma unidade informacional, deixando de fazer sentido a contagem de UI dentro da cláusula. O aspecto Grau de Informatividade, então, recaiu sobre o período em que a cláusula se encontra, pois verificamos as cláusulas que se combinam à cláusula relativa apositiva "desgarrada", formando um complexo clausal. Para tanto, elaboramos a escala de Grau de informatividade, de modo que, quanto mais baixo for o grau de informatividade, maior é a evidência/ destaque dado à cláusula relativa apositiva "desgarrada" no texto, pois, já que ela se apresenta individualmente, ela própria é a sentença. Quanto mais elevado for o grau de informatividade, significa dizer que mais cláusulas estão agregadas à cláusula relativa apositiva "desgarrada", ampliando o quantum de informação do período, diminuindo, assim, o foco informacional da relativa. Observemos os resultados obtidos na tabela a seguir:

Tabela 2 - Distribuição das unidades informacionais

\begin{tabular}{c|c|c}
\hline Grau de unidades informacionais & \multicolumn{2}{|c}{ Total } \\
\hline & Oco. & $\%$ \\
\hline 1 UI - baixo & 353 & 70,6 \\
\hline 2 UI - médio & 110 & 22,0 \\
\hline 3 UI - alto & 26 & 5,2 \\
\hline 4 UI - elevado & 11 & 2,2 \\
\hline Total: & $\mathbf{5 0 0}$ & $\mathbf{1 0 0}$ \\
\hline
\end{tabular}

Fonte: Souza (2020).

Por meio da Tabela (2), percebemos que a preferência do usuário da língua é o grau de informatividade baixo, ou seja, a presença de apenas uma cláusula: a cláusula relativa apositiva "desgarrada". Já em 2,2\% dos casos (11 oco.), o grau de informatividade foi classificado como elevado, de modo que o complexo clausal é constituído por 4 cláusulas (o máximo identificado em todo o corpus): a relativa "desgarrada" combinada a mais três cláusulas hipotáticas e/ou paratáticas. Verifica-se que, de uma forma geral, a "desgarrada" não se combina a outras cláusulas, já que o baixo grau de informatividade registrou 70,6\% (353 oco.) e o médio com 22,0\% (110 oco.) quando tínhamos somente duas UI no complexo clausal. Somando os graus alto e elevado, verificamos que os dois juntos não chegaram a $10 \%$ de todos os dados (500 oco.) analisados. Listamos a seguir alguns exemplos para ilustrar a 
combinação de cláusulas composta pela cláusula relativa apositiva "desgarrada" ou a "desgarrada" e uma ou mais cláusula(s) hipotática(s) e/ou paratática(a):

Exemplo (8) a) Sem amor, sem açúcar, sem alegrias... sem tristezas. Voltei... Porque provei que posso seguir! Não voltei pra voce, mas para mim! Tô voltando para a minha vida... Para o meu ego... Para meus amigos... Quero chegar logo! Pular no colo da minha mãe e nos braços de quem amo! Voltei a ser a criança de antes. A qual havia sido sequestrada pelas tantas dificuldades $\boldsymbol{e}$ problemas da vida. Que derrepente virou adulto sem face... Não quero mais ir embora... Quero ficar pra SEMPRE, aprendendo o que é viver! Vou arriscar toda vez que sentir vontade... Vou ser ousado, cada vez que meu coração pulsar mais forte. Vou voltar... Tõ voltando... Voltei!

b) De acordo com o policial Sd Sdney que primeiro chegou ao local, o menor é conhecido da polícia. Segundo ele o mesmo já teria se envolvido em uma troca de tiros contra uma guarnição da polícia. "«Ele se envolveu numa ocorrência com a polícia. Onde ele atirou contra a viatura e foi alvejado num dos bracos"». Relatou o Sd Sdney. Com ele os policiais encontraram um revólver.

c) Nelson, primeira vez que estou entrando em seu site; moro em Brumado e dia (26/11/08 a 28/11/08) irá ter um feira de ciências em minha escola. Cujo o tema será Cultura AfroBrasileira, então a minha professora mandou eu falar sobre a religião... Pesquisei muito em sites como esse, mas não obtive ajuda, eu irei vestir de (Yamim), so que eu não obtive ajuda para conseguir a minha fala, preciso muito até o dia 23/11/08 para Decorar.

d) A sua conversa e a sua caminhada devem ser com Deus somente e com aqueles que te demonstrarem amor apesar de tudo, amor incondicional, aqueles que sabem quem você é apesar de não te reconhecerem em meio aos momentos de reestruturação que você vive por a depressão. Porque ninguém fica como sempre foi durante os períodos de depressão. E é o amor, e não acusações, que vai ajudar em isso. A civilização ocidental abomina a depressão. Muitos cristãos abominam a depressão. $O$ que é previsível, pois vivemos em uma sociedade hedonista, onde tristeza, melancolia e não estar com "« alegria todo dia "» é visto somente como um mal e não como um processo necessário de melhoria e avanco espirituais.

No Exemplo 8, letra (a), trouxemos um exemplo de grau de informatividade baixo contendo apenas a cláusula relativa apositiva "desgarrada" - A qual havia sido sequestrada pelas tantas dificuldades e problemas da vida. 353 ocorrências (de 500 oco.) do corpus foram dessa forma, o que permitiu mais força, mais evidência para o comentário presente na cláusula única. Selecionamos a porção textual da letra (b) como modelo de 110 ocorrências (de 500 oco.) do grau de informatividade que aqui chamamos de médio. Nela, observamos dois blocos de unidade informacional: a cláusula relativa apositiva "desgarrada" - Onde ele atirou contra a viatura -, e uma cláusula paratática que estende o significado da primeira cláusula - e foi alvejado num dos braços. Pelo período complexo ter duas UI, consequentemente, ele traz mais informação para o leitor, diminuindo o direcionamento de foco informacional da cláusula relativa apositiva "desgarrada".

Na letra (c), a combinação clausal destacada em negrito é modelo de apenas 26 dados (de 500 oco.) rotulados como grau de informatividade alto por conter 3 unidades informacionais: (i) uma cláusula relativa apositiva "desgarrada" - Cujo o tema será Cultura 
Afro-Brasileira; (ii) uma hipotática de realce - então a minha professora mandou; (iii) eu falar sobre a religião. Percebemos que o grau de informatividade alto, com 3 UI, é bem incomum de ocorrer, já que só obtivemos 5,2\% em 500 dados.

Mais raro ainda foram os casos de grau de informatividade elevado, 11 dados (2,2\%) de 500 oco. A letra (d) é um exemplo dessa combinação de cláusulas constituída por 4 blocos de informação. Nela, temos: (i) uma cláusula relativa apositiva "desgarrada" - O que é previsível; (ii) uma cláusula hipotática de realce - pois vivemos em uma sociedade hedonista; (iii) uma hipotática que expande o significado da cláusula anterior - onde tristeza, melancolia e não estar com "« alegria todo dia "» é visto somente como um mal; (iv) e uma paratática que estende o significado da cláusula anterior - e não como um processo necessário de melhoria e avanço espirituais. Em suma, observamos por esses dados que quanto menos cláusulas agregadas à cláusula relativa apositiva "desgarrada", mais ênfase ela recebe porque a Figura não se expande tanto, centrando-se, assim, apenas no Evento da "desgarrada".

Levando em consideração o estudo sobre a Estrutura Informacional das cláusulas relativas apositivas "desgarradas" sob a ótica da GSF de Halliday e Matthiessen (2014), podemos validar a hipótese de que o escrevente usa intencionalmente a ruptura sintática (formalmente utilizando o sinal gráfico ponto final) com a finalidade de conduzir o leitor para uma informação com o status de Nova (informação não recuperável no cotexto). Como vimos na análise dos exemplos, o escrevente cede as informações pouco a pouco durante a construção do seu Texto, movimentando-se para trás (inserindo o elemento Dado) e para frente (elemento Novo).

Devemos ressaltar que o corpo da cláusula é basicamente constituído de informação Nova, visto que a informação Dada está encapsulada em um elemento gramatical pronome relativo (geralmente vazio de significado) e que ganha verdadeiro significado quando a referenciação é ativada, estabelecendo-se uma relação entre a relativa e o referente (SN, SAdv ou porção textual). Assim, na relativa "desgarrada", o escrevente contextualiza previamente por meio do conector o seu comentário, tornando-o coeso. Quanto ao grau de informatividade, vimos que, quanto mais cláusulas agregadas à cláusula relativa apositiva "desgarrada", menor é o foco informacional no comentário da cláusula relativa e, por esse motivo, grau de informação alto (com 3 UI) e elevado (com 4 UI) são bem raros, dentro do corpus averiguado com 500 cláusulas relativas apositivas "desgarradas". Sendo assim, verificamos uma preferência dos usuários por um grau de informatividade baixo (com 1 UI), ou seja, a cláusula relativa apositiva "desgarrada" funcionando de forma autônoma, para que ela ganhe maior grau de proeminência focal. 


\section{Considerações}

A metafunção TEXTUAL, da Gramática Sistêmico-Funcional (HALLIDAY; MATTHIESSEN, 2014), revela a sua importância, visto que, por meio dela, podemos verificar a intencionalidade do escrevente ao evidenciar/pôr em relevo o seu comentário, dirigindo o leitor para a informação que realmente é importante (do ponto de vista do escrevente) e, concomitantemente, dirige o leitor para a informação com o estatuto de Nova (do ponto de vista do leitor).

Mesmo sem uma análise acústica/prosódia da "desgarrada" é possível fazer um estudo do estatuto informacional do comentário da cláusula "desgarrada" por meio dos recursos linguísticos disponíveis. Devemos registrar que o elemento Novo da Estrutura Informacional das cláusulas relativas apositivas "desgarradas" coincide com o Rema da Estrutura Temática, já que em todas as 500 ocorrências do nosso corpus, as cláusulas relativas apositivas “desgarradas" seguiram um padrão não marcado. Sendo assim, verificamos um padrão TemaRema/ Dado-novo. O baixo índice de outras unidades informacionais agregadas à cláusula relativa $(7,4 \%$ se juntarmos os dados com 3 UI e 4 UI), reforça o fenômeno do "desgarramento", pois quanto mais baixo for o grau de informatividade do período, maior é o foco informacional quando a cláusula funciona de forma autônoma.

Portanto, acreditamos que este artigo apresenta subsídios para o estudo das cláusulas relativas apositivas "desgarradas" e, mais especificamente, para as pesquisas relacionadas ao fenômeno do "desgarramento" em língua portuguesa, uma vez que o nosso foco aqui era a metafunção TEXTUAL. Por outro lado, muito há ainda o que ser investigado na cláusula observada, já que a GSF nos dá um leque de possibilidades muito amplo e muito rico, por estar embasada na experiência de mundo do ser humano.

\section{Referências}

CHAFE, W. L. The deployment of consciousness in the production of a narrative. In: CHAFE, W. L. (Org.). The pears stories: cognitive, cultural and linguistic aspects of narrative production. New Jersey: Ablex Publishing Co., 1980. p. 9-50.

CUNHA, M. A.; SOUZA, M. M. Transitividade e seus contextos de uso. v. 2. São Paulo: Cortez, 2011.

DAHLET, V. As (man)obras da pontuação: usos e significações. São Paulo: Associação Editorial Humanitas, 2006. 
DAVIES, M. Web/Dialetos. In: Corpus do Português (2016). Provo: Brigham Young University, 2016. Disponível em: https://www.corpusdoportugues.org/xp.asp. Acessado em 10 dez. 2018.

DECAT, M. B. N. Estruturas Desgarradas em Língua Portuguesa. Campinas: Pontes Editores, 2011.

DECAT, M. B. N. Orações relativas apositivas 'desgarradas' no português em uso. In: BISPO, E. B.; OLIVEIRA, M. R. (Orgs.). Orações relativas no português brasileiro: diferentes perspectivas. Niterói: Editora da UFF, 2014. p.157-189.

FUZER, C.; CABRAL, S. R. C. Introdução à gramática sistêmico-funcional em língua portuguesa. 1. ed. Campinas: Mercado de Letras, 2014.

HALLIDAY, M. A. K.; MATTHIESSEN, C. M. I. M. An introduction to functional grammar. 4. ed. Londres-Nova York: Routledge, 2014 [1985].

KOCH, I. G. V.; ELIAS, V. M. Ler e compreender: os sentidos do texto. 2. ed. São Paulo: Contexto, 2008.

SANKOFF, D.; TAGLIAMONTE, S.; SMITH, E. Goldvarb X: A variable rule application for Macintosh and Windows. Department of Linguistics: University of Toronto, 2005.

SOUZA, K. P. F. "Exposição de moveis | A qual se fechará brevemente": Estudo de cláusulas relativas apositivas "desgarradas" em textos jornalísticos. 2016.191 f. Dissertação. (Mestrado em Letras Vernáculas) - Programa de Pós-Graduação em Letras Vernáculas, Universidade Federal do Rio de Janeiro, Rio de Janeiro, 2016.

SOUZA, K. P. F. Desgarramento de cláusulas relativas apositivas: comparação de três sincronias do PB. In: RODRIGUES, V. V. (Org.). Desgarramento de cláusulas em português: usos e descrição. São Paulo: Blucher, 2019. p. 39-60.

SOUZA, K. P. F. A influência da interpessoalidade nas cláusulas relativas apositivas “desgarradas" segundo a gramática sistêmico-funcional. 2020. 256 f. Tese. (Doutorado em Letras Vernáculas) - Programa de Pós-Graduação em Letras Vernáculas, Universidade Federal do Rio de Janeiro, Rio de Janeiro, 2020.

SOUZA, K. P. F.; RODRIGUES, V. V. Adjetivas explicativas e o "desgarramento" em sala de aula. In: RODRIGUES, V. V. (Org.). Pesquisas em sintaxe e sua aplicação em sala de aula. Rio de Janeiro: Editorarte, 2018. p. 122-138.

SOUZA, K. P. F.; SILVESTRE, R. C. P. E. "Desgarramento" de cláusulas hipotáticas. In: COELHO, F. A. C.; SILVA, J. E. N.; CONFORTE, A. N. (Orgs.). Descrição e ensino de língua portuguesa: temas contemporâneos. Série Língua Portuguesa e Ensino. 1ed. Rio de Janeiro: Dialogarts, 2018, v. 6. p. 385-497.

PRINCE, E. F. Toward a taxonomy of given-new information. In: COLE, P. (ed.). Radical Pragmatics. New York: Academic Press, 1981. p. 223-255. 
Revista (Con)Textos Linguísticos, Vitória, v. 14, n. 28, p. 412-432, 2020 | e-ISSN 1982-291X | ISSN 2317-3475

Revista do Programa de Pós-Graduação em Linguística da UFES | periodicos.ufes.br/contextoslinguisticos

\section{Sobre a autora}

Karen Pereira Fernandes de Souza (Orcid iD http://orcid.org/0000-0002-0544-2778)

Doutora e mestra em Letras Vernáculas pela Universidade Federal do Rio de Janeiro (UFRJ); especialista em Metodologia do Ensino de Língua Portuguesa pela AVM Educacional; graduada em Letras - Português/Francês pela UFRJ.

Recebido em junho de 2020.

Aprovado em setembro de 2020. 